\title{
Functionalized dicationic ionic liquids: Green and efficient alternatives for catalysts in phthalate plasticizers preparation
}

\author{
NEGAR ZEKRI, REZA FAREGHI-ALAMDARI* and ZAHRA KHODARAHMI \\ Faculty of Chemistry and Chemical Engineering, Malek-Ashtar University of Technology, \\ Tehran, 16765-3454, I. R. Iran \\ e-mail: reza_fareghi@yahoo.com
}

MS received 9 January 2016; revised 22 April 2016; accepted 14 June 2016

\begin{abstract}
Two highly acidic, imidazolium-based, functionalized dicationic ionic liquids (FDCILs) were synthesized and characterized by FTIR, ${ }^{1} \mathrm{H}$ NMR and ${ }^{13} \mathrm{C}$ NMR. The synthesized FDCILs were used as efficient and green catalysts in the synthesis of phthalate plasticizers through esterification of phthalic anhydride ( $\mathrm{PhA})$ with ethanol, n-propanol and n-butanol. Among these two FDCILs, (dimethyl-4-sulfobutyl-ammonium) 1,2ethan-1-methyl-imidazolium-sulfonic acid hydrogen sulfate performed better. The catalytic activity of FDCIL is related to the density of acidic groups on it and the length of the carbon chain in the cationic part. The influences of the reaction temperature, catalyst dosage, and molar ratio of phthalic anhydride to alcohol on the esterification reaction were investigated. The reusability of the catalyst in these reactions was studied too. The diester phthalates were obtained up to $98.8 \%$ yield. The products can be separated easily by decantation from the reaction mixture.
\end{abstract}

Keywords. Acidic dicationic ionic liquids; highly acidic catalysts; esterification; phthalate plasticizers.

\section{Introduction}

Phthalate plasticizers are the main plasticizers used as softening agents in various industrial applications. ${ }^{1}$ These compounds are mainly used as plasticizers for cellulosic resins and some vinyl ester resins, PVC and nitrocellulose lacquers. ${ }^{2}$ Diethyl, dibutyl and dioctyl phthalates are the most common plasticizers used in the formulation of double-based solid propellants. ${ }^{3,4}$ Phthalates are manufactured by esterification reaction between corresponding acids/ anhydrides and alcohols in the presence of acidic catalysts. ${ }^{5}$ Various catalysts have been reported for this reaction. Sulfuric acid has been mainly used in traditional and industrial esterification of phthalates. ${ }^{2}$ Many heterogeneous catalysts such as heteropoly acids, ${ }^{6}$ zirconium titanium phosphate, ${ }^{7}$ and zeolites ${ }^{8}$ are used as catalysts for esterification of phthalic anhydride. However, the use of sulfuric acid causes some problems such as formation of byproducts, corrosion, loss of catalyst, toxicity, tedious work-up and environmental problems. ${ }^{9}$ Heterogeneous catalysts can give some benefits; for example, easy work-up, catalyst reusability and avoidance of corrosion. ${ }^{10}$ Despite of the benefits of these catalysts,

*For correspondence some suffer from disadvantages such as limited accessibility of the matrix-bound catalyst, rapid deactivation and high molecular weight/active-site ratios. ${ }^{9}$ Therefore, development of an efficient, highly selective, environmentally benign and easy method using novel catalysts for preparation of phthalate esters will be interesting.

Among the variety of catalysts, ionic liquids (ILs) have the advantages of liquid and solid phase together. ${ }^{11}$ Task-specific ionic liquids (TSILs) have received great attention over the past few decades performing as catalyst and solvent in organic chemistry due to their unique properties such as environmentally friendly nature, nonvolatility, high polarity, and good thermal and chemical stabilities. ${ }^{12-16}$ TSIL can be defined as association of cation and anion, to which a functional group is covalently bonded that confers the assembly a specific task. In general, TSILs have been used as substitutes for conventional homogenous and heterogeneous acid catalysts. ${ }^{17}$

A new approach using alkyl sulfonated functionalized ILs has drawn more efforts due to their acidic properties and water solubility. Recently some imidazolium and pyridinium based acidic ILs were used as catalyst to prepare phthalate plasticizers. ${ }^{9,18}$ Meanwhile, multifunctional ILs especially dicationic ILs (DCILs) are attracting more attention as alternative reaction media in green chemistry than conventional mono-cationic ILs. ${ }^{19,20}$ The DCIL contains two head groups and aliphatic chain 
linked by either a rigid or flexible spacer. ${ }^{21}$ Functionalization ability of DCILs were explored to design their structures with respect to cations, anions and length of their linker chains in between cations. ${ }^{22}$

A few DCILs were used as catalysts in the esterification reaction. Basic binuclear functional ILs were synthesized and used as catalyst in the preparation of biodiesel through transesterification from cottonseed oil, ${ }^{23}$ and esterification of organic acids with ethanol was carried out in the presence of a dicationic ionic liquid. ${ }^{24} \mathrm{~A}$ group of imidazolium-based DCILs have been used for esterification of alcohols by carboxylic acids. ${ }^{25}$ In these reactions, researchers have focused on the synthesis and application of geminal DCILs (same cationic counterparts). Recently, we synthesized dual dicyanamide-based ionic liquids consisting of coupled ammonium-imidazolium cationic structures and also unsymmetrical dicationic azide functionalized ionic liquids and studied their physical and thermal properties. ${ }^{26,27}$ Continuing our research activities in the field of synthesis, characterization and application of ionic liquids, ${ }^{26-32}$ we decided to synthesize the geminal and unsymmetrical (different cationic counterparts) DCILs with traditional counter anion, $\mathrm{HSO}_{4}^{-}$. The catalytic activities of the synthesized FDCILs were tested for esterification of phthalic anhydride with ethanol, npropanol and n-butanol (Scheme 1). The structures of FDCILs used in this study are shown in Figure 1.

\section{Experimental}

\subsection{Materials and apparatus}

All reagents and solvents were purchased from Merck and Fluka chemical companies. The newly synthesized FDCILs were characterized by ${ }^{1} \mathrm{H}$ NMR and ${ }^{13} \mathrm{C}$ NMR on a Bruker DRX - 300 spectrometer. Chemical shifts are reported relative to TMS as an internal standard. The solvents used were DMSO and $\mathrm{D}_{2} \mathrm{O}$. FT-IR spectra were obtained on a Nicolet 800 instrument. Elemental analyses were obtained using a Heraeous CHN analyzer. Melting points were determined using melting point IA 8103 apparatus. Quantitative product analysis was conducted by gas chromatography on Hewlett Packard HP-5890 instrument equipped with HP-1 column (30 m long, $0.5 \mathrm{~mm}$ diameter), and flame ionization detector (FDI), using $\mathrm{N}_{2}$ as carrier gas at a flow rate of $2 \mathrm{~mL} \cdot \mathrm{min}^{-1}$.

\subsection{Preparation of functionalized dicationic ionic liquids (FDCILs)}

2.2a Synthesis of 4-((2-Hydroxyethyl) dimethyl azanyl) butan-1-sulfate(1):2-(Dimethyl amino)-ethanol (10.1 mL, $100 \mathrm{mmol}$ ) was dissolved in tolueneunder vigorous stirring. $10.2 \mathrm{~mL}$ ( $100 \mathrm{mmol}$ ) of 1,4-butane sulfonate was poured slowly in an ice bath. After the pouring was finished, the
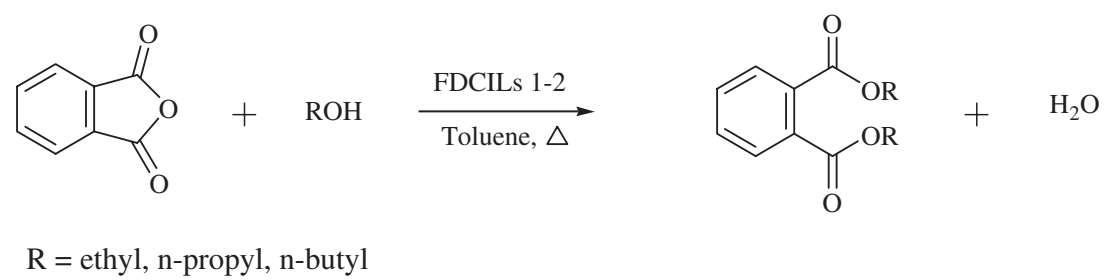

Scheme 1. Esterification of phthalic anhydride with alcohols using FDCIL1 and 2.

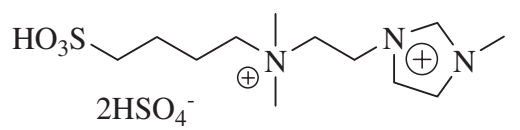

(FDCIL1)

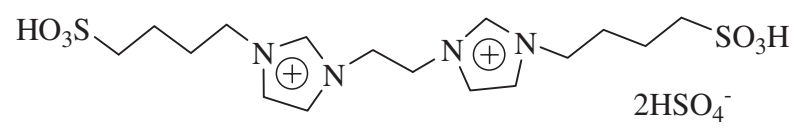

(FDCIL2)

FDCIL1: [(Dimethyl-4-sulfobutyl-ammonium)-1,2-ethane-1H-imidazolium sulfonic acid] hydrogen sulfate.

FDCIL2: 3,3' -(1,2-Ethanediyl)bis[1-(4-sulfobutyl)-1H-imidazolium sulfonic acid] hydrogen sulfate.

Figure 1. Structures of FDCILs used in this study. FDCIL1: [(Dimethyl-4-sulfobutyl-ammonium)-1,2ethane-1H-imidazolium sulfonic acid] hydrogen sulfate. FDCIL2: 3,3'-(1,2-Ethanediyl)bis[1-(4-sulfobutyl)-1H-imidazolium sulfonic acid] hydrogen sulfate. 
mixture was slowly heated up to $111^{\circ} \mathrm{C}$ and refluxed for $12 \mathrm{~h}$. Then, the reaction mixture was filtered to get the white precipitate. The precipitate was washed thrice with diethyl ether and dried at $80^{\circ} \mathrm{C}$ for $5 \mathrm{~h}$, giving (1) as a white powder (M.p. $74^{\circ} \mathrm{C}$, yield $93.8 \%$ ).

2.2b Synthesis of 4-((2-chloroethyl)dimethylazanyl) butan-1-sulfate (2): $16.1 \mathrm{~g}$ (70 mmol) of (1) was dissolved in chloroform under vigorous stirring and thionyl chloride $(5 \mathrm{~mL}, 70 \mathrm{mmol})$ was poured slowly to the reaction mixture in an ice bath. The mixture was slowly heated up to $62^{\circ} \mathrm{C}$ and refluxed for $12 \mathrm{~h}$. Then it was washed with chloroform thrice and heated at $50^{\circ} \mathrm{C}$ for $2 \mathrm{~h}$, giving (2) as a light yellow viscous liquid (yield $94.7 \%)$.

2.2c Synthesis of (dimethyl-4-sulfobutyl-ammonium)1,2ethan-1 methyl-imidazolium sulfate (3): $3.0 \mathrm{~g} \mathrm{(12} \mathrm{mmol)}$ of (2) and 1-methyl imidazole (1.0 g, $12 \mathrm{mmol})$ were dissolved in acetonitrile under vigorous stirring and refluxed for $12 \mathrm{~h}$. Then, the reaction mixture was filtered to get the white precipitate. The precipitate was washed thrice with diethyl ether and dried at $80^{\circ} \mathrm{C}$ for $5 \mathrm{~h}$, giving (3) as a white powder (M.p. $109^{\circ} \mathrm{C}$, yield $94.5 \%)$.

2.2d Synthesis of (dimethyl-4-sulfobutyl-ammonium)1, 2-ethan-1-methyl-imidazolium-sulfonic acid hydrogen sulfate (FDCIL1): $2.56 \mathrm{~g}(10 \mathrm{mmol})$ of (3) was dissolved in methanol and sulfuric acid $98 \%(10.6 \mathrm{~mL}$, $20 \mathrm{mmol}$ ) was poured slowly. The mixture was heated up to $60^{\circ} \mathrm{C}$ and stirred for $12 \mathrm{~h}$. Then, the reaction mixture was washed thrice with diethyl ether and heated at $70^{\circ} \mathrm{C}$ for $1 \mathrm{~h}$, giving FDCIL1. Compound FDCIL1: Light yellow viscous liquid; yield 96.3\%; ${ }^{1} \mathrm{H}$ NMR (300 MHz, $\mathrm{D}_{2} \mathrm{O}, 25^{\circ} \mathrm{C}$, TMS, $\left.\delta \mathrm{ppm}\right) 1.07-1.13(\mathrm{~m}, 2 \mathrm{H}$, $\left.\mathrm{HSO}_{3} \mathrm{CH}_{2} \mathrm{CH}_{2} \mathrm{CH}_{2}\right), 1.24-1.26\left(\mathrm{~m}, 2 \mathrm{H}, \mathrm{HSO}_{3} \mathrm{CH}_{2} \mathrm{C}\right.$ $\left.\underline{\mathrm{H}}_{2}\right), 2.29\left(\mathrm{t}, J=7.48 \mathrm{~Hz}, 2 \mathrm{H}, \mathrm{HSO}_{3} \mathrm{CH}_{2} \mathrm{CH}_{2} \mathrm{CH}_{2} \mathrm{CH}_{2}\right.$ ), 2.47 (s, $\left.6 \mathrm{H}, \mathrm{N}\left(\mathrm{CH}_{3}\right)_{2}\right), 2.66$ (s, 3H, Im- $\left.\underline{\mathrm{H}}_{3}\right), 2.70-2.76$ $\left(\mathrm{m}, 2 \mathrm{H}, \mathrm{HSO}_{3} \mathrm{CH}_{2}\right), 3.04$ (t, $J=6.0 \mathrm{~Hz}, 2 \mathrm{H}, \mathrm{N}\left(\mathrm{CH}_{3}\right)_{2}$ $\left.\mathrm{CH}_{2} \mathrm{CH}_{2} \mathrm{Im}\right), 3.30$ (t, $J=6.0 \mathrm{~Hz}, 2 \mathrm{H}, \mathrm{N}\left(\mathrm{CH}_{3}\right)_{2} \mathrm{CH}_{2}$ $\left.\mathrm{CH}_{2} \mathrm{Im}\right), 6.75$ (s, 1H, $\left.\mathrm{H}_{\mathrm{Im}}\right), 6.76\left(\mathrm{~s}, 1 \mathrm{H}, \mathrm{H}_{\mathrm{Im}}\right), 7.94$ (s, $\left.1 \mathrm{H}, \mathrm{H}_{\mathrm{Im}}\right){ }^{13} \mathrm{CNMR}\left(75 \mathrm{MHz}, \mathrm{D}_{2} \mathrm{O}, 25^{\circ} \mathrm{C}\right.$, TMS, $\left.\delta \mathrm{ppm}\right)$ 20.10, 20.21, 34.69, 49.24, 50.40, 54.55,63.61, 64.12, $118.72,118.76,122.33$; FT-IR $(\mathrm{KBr}) v / \mathrm{cm}^{-1}: 2953$, 1636, 1474, 1230, 1166, 1150, 881, 591; Anal. Calcd. for $\mathrm{C}_{12} \mathrm{H}_{27} \mathrm{O}_{11} \mathrm{~N}_{3} \mathrm{~S}_{3}$ Calcd. C, 29.69; H, 5.56; N, 8.65\% Found C, 29.64; H, 5.63; N, 8.81\%.

2.2e Synthesis of 1, 1'-(1, 2- ethanediyl) bis-1H-imidazolium (4): Imidazole (1.36 g, $20 \mathrm{mmol})$, sodium hydroxide $(0.4 \mathrm{~g}, 10 \mathrm{mmol})$ and dimethyl sulfoxide $20 \mathrm{~mL}$ were mixed and stirred magnetically at $60^{\circ} \mathrm{C}$ until imidazole was dissolved. Subsequently, $0.8 \mathrm{~mL}$ (10 mmol) of 1,2-dibromoethane was added dropwise into the mixture at $60^{\circ} \mathrm{C}$ and stirred continuously for $2 \mathrm{~h}$. After that, the reaction mixture was dumped into cold water, and settled for $3 \mathrm{~h}$ to form (4) as a white solid product (M.p. $84^{\circ} \mathrm{C}$, yield $94.8 \%$ ).

2.2f Synthesis of 3, 3'-(1, 2-ethanediyl) bis [1-(4-sulfobutyl)-1H-Imidazoliumdisulfate (5): $2.64 \mathrm{~g}(0.02 \mathrm{~mol})$ of (6) was mixed with $4.09 \mathrm{~mL}(0.04 \mathrm{~mol}) 1$, 4-butane sulfonate under stirring at room temperature for $72 \mathrm{~h}$. After solidification of the mass, the product was washed three times with diethyl ether and dried at $120^{\circ} \mathrm{C}$ for $2 \mathrm{~h}$, giving (5) as a white powder (M.p. $124^{\circ} \mathrm{C}$, yield $96.3 \%)$.

2.2g Synthesis of 3,3'-(1,2-ethanediyl)bis[1-(4-sulfobutyl)-1H-imidazolium hydrogen sulfate (FDCIL2): $2 \mathrm{~g}(5 \mathrm{mmol})$ of (5) was dissolved in methanol and $0.5 \mathrm{~mL}$ $(10 \mathrm{mmol})$ of sulfuric acid $98 \%$ was added slowly. The mixture was heated up to $60^{\circ} \mathrm{C}$ and stirred for $6 \mathrm{~h}$. The reaction mixture was washed with diethyl ether and toluene three times and heated at $120^{\circ} \mathrm{C}$ for $1 \mathrm{~h}$, giving FDCIL2. Compound FDCIL2: Light yellow viscous liquid; yield 95.3\%; ${ }^{1} \mathrm{H}$ NMR $\left(300 \mathrm{MHz}, \mathrm{D}_{2} \mathrm{O}, 25^{\circ} \mathrm{C}\right.$, TMS, $\delta$ ppm) 1.39-1.456 (m, 4H, $\mathrm{HSO}_{3} \mathrm{CH}_{2} \mathrm{CH}_{2} \mathrm{C}_{2}$ ), 1.63-1.95 (m, 4H, $\left.\mathrm{HSO}_{3} \mathrm{CH}_{2} \mathrm{CH}_{2}\right), 3.11(\mathrm{t}, J=5.8 \mathrm{~Hz}$, $\left.4 \mathrm{H}, \mathrm{HSO}_{3} \mathrm{C}_{2}\right), 3.33\left(\mathrm{~s}, 4 \mathrm{H}, \operatorname{Im}\left(\mathrm{C}_{2}\right)_{2} \mathrm{Im}\right), 4.33(\mathrm{t}, 4 \mathrm{H}$, $\left.J=5.4 \mathrm{~Hz}, \mathrm{HSO}_{3} \mathrm{CH}_{2} \mathrm{CH}_{2} \mathrm{CH}_{2} \underline{\mathrm{CH}}_{2}\right), 768(\mathrm{~d}, J=6.9$ $\left.\mathrm{Hz}, 4 \mathrm{H}, \mathrm{H}_{\mathrm{Im}}\right), 8.36\left(\mathrm{~s}, 2 \mathrm{H}, \mathrm{H}_{\mathrm{Im}}\right) ;{ }^{13} \mathrm{CNMR}(75 \mathrm{MHz}$, $\mathrm{D}_{2} \mathrm{O}, 25^{\circ} \mathrm{C}$, TMS, $\delta$ ppm) 23.69, 24.08, 49.06, 49.87, 54.63, 121.07, 121.17, 123.69; FT-IR (KBr) $v / \mathrm{cm}^{-1}$ : 3422, 3140, 2939, 1638, 1448, 1350, 1302, 1188, 1066, 784, 603; Anal. Calcd. for $\mathrm{C}_{16} \mathrm{H}_{30} \mathrm{O}_{14} \mathrm{~N}_{4} \mathrm{~S}_{4}$ Calcd. C, 30.48; H, 4.76; N, 8.89\% Found C, 30.36; H, 4.80; N, $8.92 \%$.

\subsection{General procedure for the synthesis of phthalate plasticizers with FDCIL1,2}

Weighed amounts of phthalic anhydride, alcohol (ethanol, n-propanol or n-butanol), ionic liquid and toluene (as solvent) were mixed in a flask equipped with a reflux condenser, dean-stark and magnetic stirring apparatus. The reaction mixture was refluxed until completion of the reaction. Completion of the reaction was monitored by TLC (EtOAc/n-hexane 2:5). After completion of the reaction, the mixture was washed with ethyl acetate to separate the catalyst. Then, solvents were removed under reduced pressure at $90^{\circ} \mathrm{C}$ and the residue 
was purified by column chromatography to afford pure products.

\section{Results and discussion}

In this study, highly acidic FDCILs were synthesized with high yields using multistep synthetic route as shown in Scheme 2. The structure of these ionic liquids were elucidated by NMR and FT-IR spectroscopy as well as elemental analysis. The acidity of FDCILs was determined in ethanol (Table 1). Two kinds of FDCILs of this study showed strong acidity. This is the main reason why they could efficiently promote the esterification reaction.

In order to optimize the esterification reaction conditions, effect of some parameters such as reaction temperature, catalyst dosage and molar ratio of phthalic anhydride to alcohol on the synthesis of phthalate diesters were studied. After that, phthalate diesters were synthesized using phthalic anhydride and various
Table 1. The $\mathrm{pH}$ value of FDCILs in ethanol at concentration of 1 mmol.L $\mathrm{L}^{-1}$ at $298 \mathrm{~K}$.

\begin{tabular}{lll}
\hline Ionic Liquid & FDCIL1 & FDCIL2 \\
\hline $\mathrm{pH}$ value & 1.09 & 1.22 \\
\hline
\end{tabular}

alcohols with FDCILs1-2 as catalyst under optimized conditions.

\subsection{Comparison the efficiency of the newly} synthesized FDCIL1-2 in the esterification reaction of phthalic anhydride with ethanol

Evaluation of the efficiency of synthesized FDCILs in the esterification of phthalic anhydride with ethanol (Scheme 3) revealed that FDCIL1 is an effective catalyst for the esterification reaction. Table 2, entries 1-2 give the yield values of the esterification of phthalic anhydride with ethanol in the presence of FDCIL1-2. These results suggested that the performance of

i) Synthesis of FDCIL1

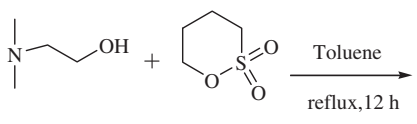

$\Theta$<smiles>CN(CCCl)CCCCOS(=O)(=O)O</smiles>

(2)

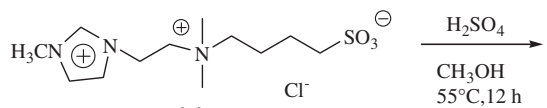

(3)

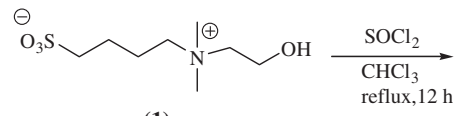

(1)

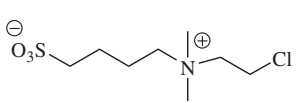

(2)
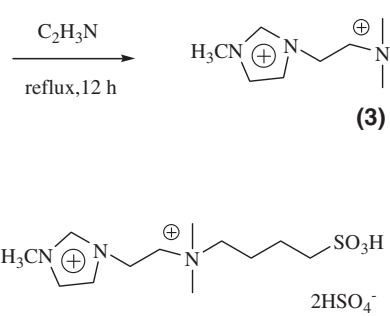

(FDCIL1)

ii) Synthesis of FDCIL2

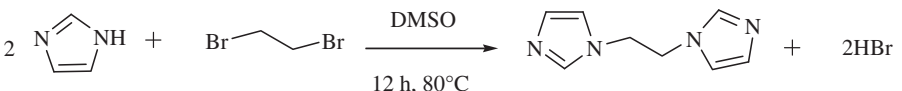

(4)

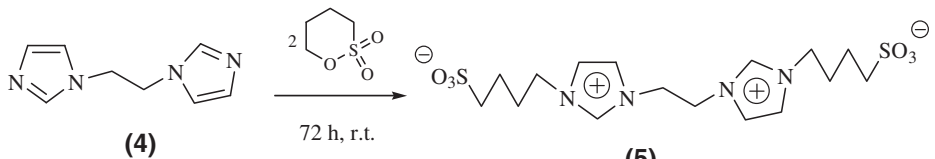

(5)

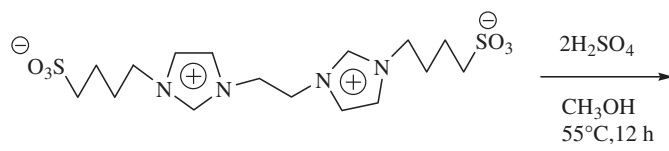

(5)

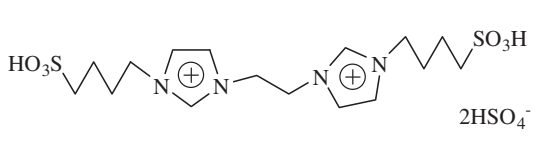

(FDCIL2)

Scheme 2. Multistep synthetic route of FDCILs 1-2. 
<smiles>CCOC1CCCCC1</smiles>

Phthalic anhydride<smiles>CCOC(=O)c1ccccc1C(=O)OCC</smiles>

Diethyl phthalate

Scheme 3. Esterification of phthalic anhydride with ethanol using FDCILs 1-2.

Table 2. Results of esterification of phthalic anhydride with different alcohols in the presence of FDCILs.

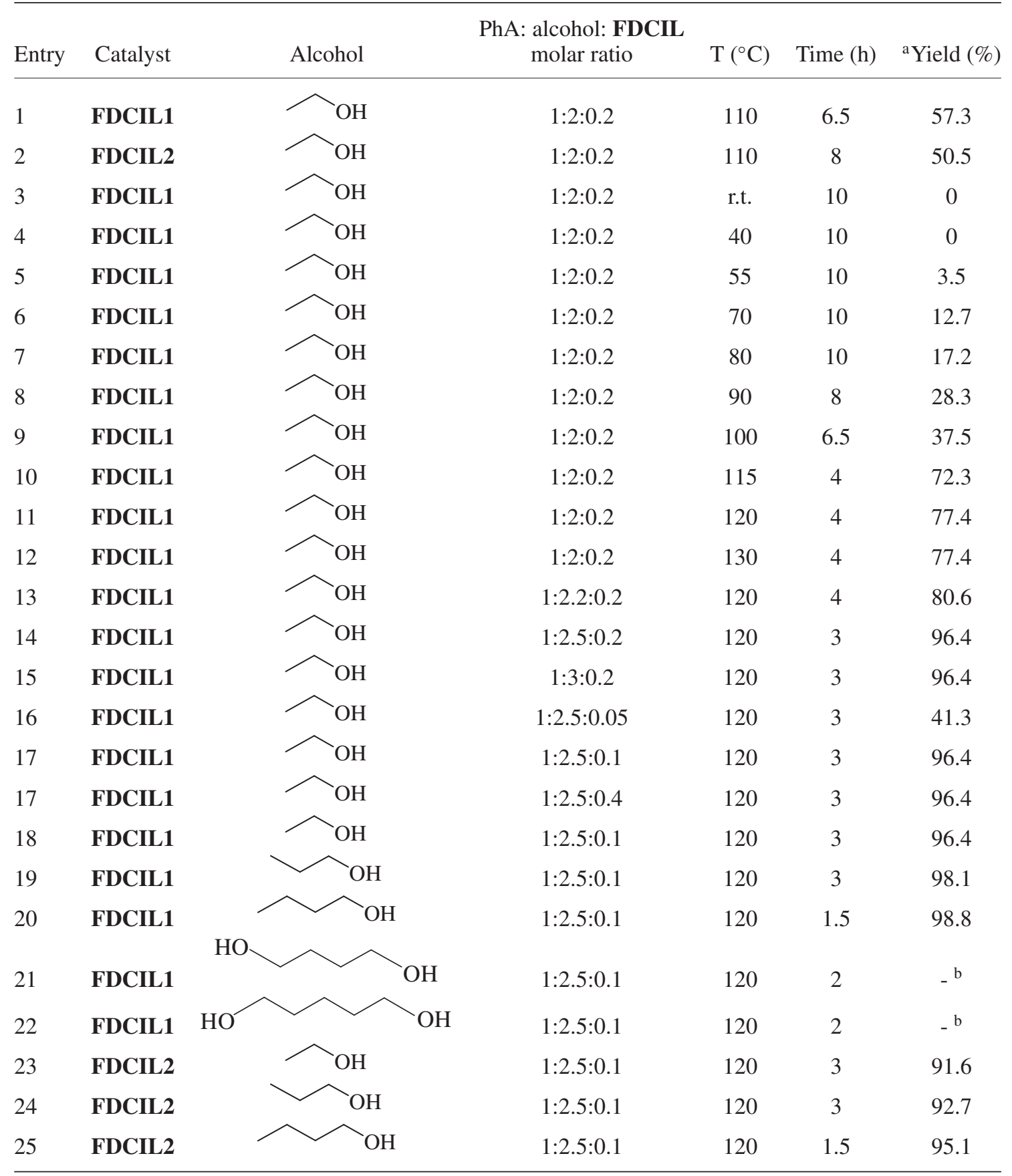

${ }^{\text {a }}$ Yields estimated by GC.

b Polymer product. 
FDCILs is dependent upon the character of the cation side chain (low lipophilic character of the FDCIL1 cation). Moreover, the $\mathrm{pH}$ values of these catalysts showed that the acidity of FDCIL1 is higher than FDCIL2 (Table 1). So, as expected, FDCIL1 performs better.

For optimization purpose, various reaction conditions for the synthesis of phthalate diesters were tested using FDCIL1 as catalyst (Table 2, entries 1, 3-18).

\subsection{Effect of the reaction temperature on esterification of phthalic anhydride}

Effect of the reaction temperature on esterification of phthalic anhydride with ethanol was studied. The results of this study are shown in Table 2, entries 1, 312. It is clear from this Table that when the reaction was carried out at room temperature, phthalic anhydride was not converted into diethyl phthalate, even after $10 \mathrm{~h}$. Esterification yield increased with a rise in temperature, reaching a maximum of $77.4 \%$ at $120^{\circ} \mathrm{C}$ (Table 2, entry 11). As can be seen from Table 2 , entry 12 , increasing the temperature above $120^{\circ} \mathrm{C}$ did not lead to any improvement. So, the optimum reaction temperature is $120^{\circ} \mathrm{C}$ (Figure 2).

\subsection{Effect of the molar ratio of reactants on esterification of phthalic anhydride}

Generally an excess amount of ethanol is necessary for esterification of phthalic anhydride; because, it can

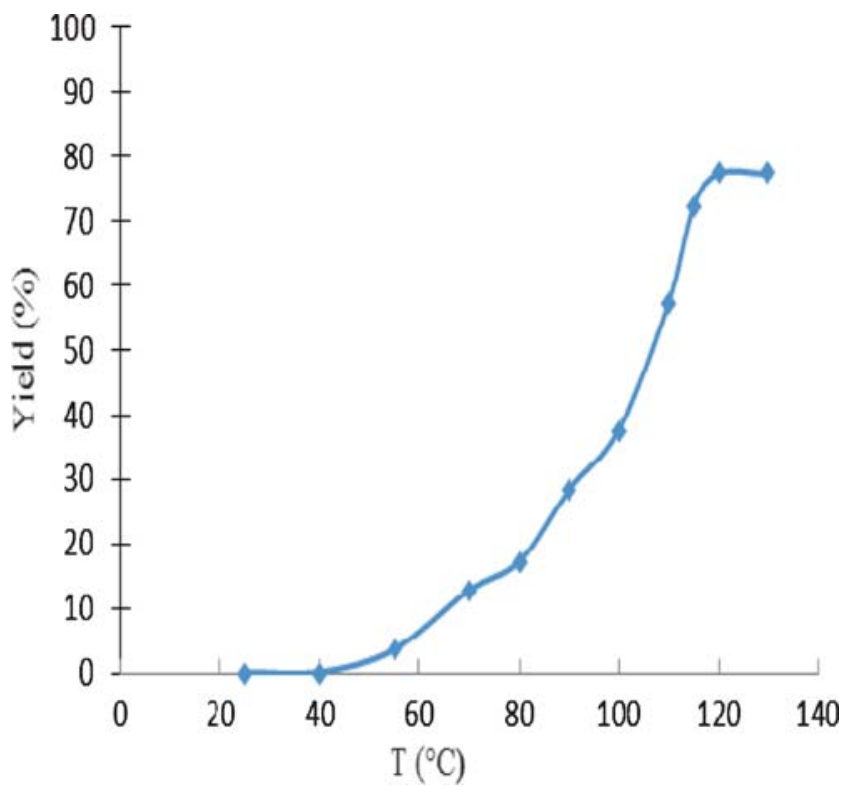

Figure 2. Effect of the reaction temperature on the esterification of phthalic anhydride with ethanol. PA: Ethanol: FDCIL1 molar ratios is 1: 2: 0.2 and the solvent is toluene. increase the rate of esterification. In addition, the optimized reaction temperature is higher than the boiling point of ethanol $\left(78^{\circ} \mathrm{C}\right)$, therefore some of it vaporized during the reaction. The influence of rectants molar ratio was studied at $120^{\circ} \mathrm{C}$, the reaction conditions and yields obtained are shown in Table 2, entries 11, 13-15. The results showed that increasing the molar ratio of phthalic anhydride to ethanol, increases the reaction yield. The highest achieved yield was $96.4 \%$ with phthalic anhydride to ethanol molar ratio of 1:2.5 (Table 2, entry 14). Further increase of this molar ratio did not increase the product yield probably because phthalic anhydride and FDCIL1 became too diluted with excess ethanol.

\subsection{Effect of catalyst concentration on esterification of phthalic anhydride}

To determine the optimum concentration of the catalyst (FDCIL1) in the esterification reaction of phthalic anhydride with ethanol, the reaction was done at $120^{\circ} \mathrm{C}$ with phthalic anhydride: ethanol molar ratio of 1:2.5 and different amounts of FDCIL1. As shown in Table 2, entries $14,16-18$, by increasing the mole ratio of phthalic anhydride: FDCIL1 from 0.05 to 0.1 , the yield of diethyl phthalate increased. But further increase in amount of the catalyst did not improve the reaction yield.

\subsection{Reusability of FDCIL1 in esterification of phthalic anhydride}

In order to examine the reusability of FDCIL1 after completion of the reaction, ethyl acetate $(2 \times 5 \mathrm{~mL})$ was added. The reaction mixture was divided into two

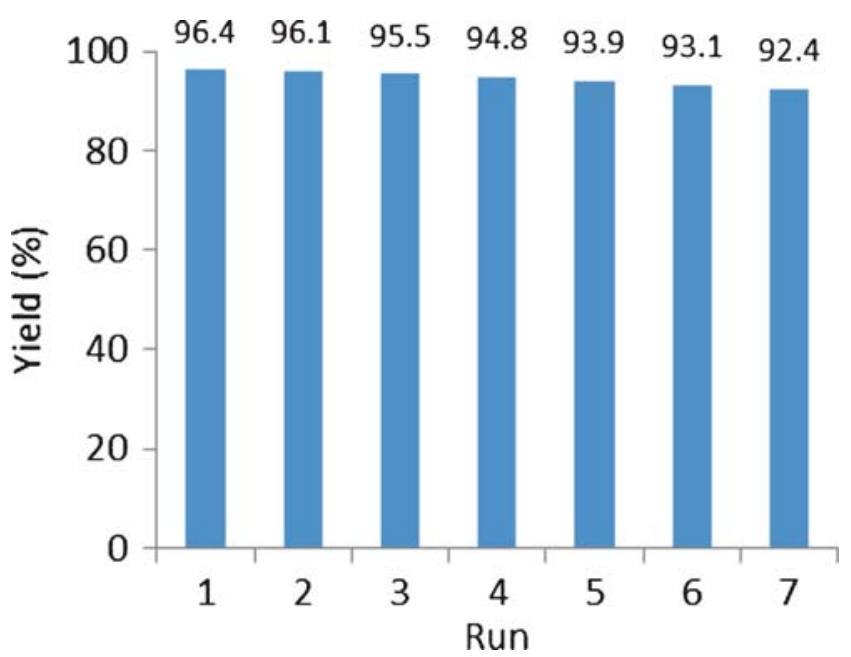

Figure 3. Reusability of FDCIL1 in the esterification reaction of phthalic anhydride with ethanol. 
layers. The upper phase contained the products and the lower phase the FDCIL1. After further extractions $(3 \times$ $5 \mathrm{~mL}$ ethyl acetate) and phase separation, the FDCIL1 was dried under vacuum for $5 \mathrm{~h}$ at $70^{\circ} \mathrm{C}$. The results of the reusability of FDCIL1 are shown in Figure 3, indicating no major decrease in the product yield even after 7 runs.

\subsection{Esterification of phthalic anhydride with various alcohols using FDCIL1-2}

Esterification of phtalic anhydride were carried out with ethanol, n-propanol and n-butanol in the presence of FDCIL1-2, and the diester product was isolated conveniently in high yield. Table 2 (entries 18-20, 23-25) shows the results of these reactions. As we explained above, FDCIL1 showed higher efficiency in the synthesis of phthalate esters (Table 2, entries 18-20). It is noteworthy to mention that the immiscibility of the phthalate diester with the FDCIL facilitated the reaction equilibrium shifting to the product side. The same result was observed in another report. ${ }^{33}$

The esterification reaction that began as a homogeneous process, ended as biphasic mixture which facilitated the separation of phthalate esters from the reaction mixture.
We also tested the esterification reaction of phthalic anhydride with diols such as 1,4-butandiol and 1,5pentanediol (Table 2, entries 21, 22). As we expected and as reported by other researchers, ${ }^{34,35}$ related polyesters were produced.

\subsection{Comparison the efficiency of FDCILs with other reported catalysts in the esterification of phthalic anhydride}

Comparison of the efficiency of FDCILs with other catalytic systems in the esterification reaction of phthalic anhydride with n-butanol was studied too (Table 3). According to Table 3, the catalysts of this study, especially FDCIL1, are more effective than other reported catalysts for the esterification reaction.

\subsection{Esterification of maleic and succinic anhydrides with ethanol in the presence of FDCIL1}

To investigate the generality and scope of this method, the optimized reaction conditions was extended to other anhydrides such as maleic and succinic anhydrides (Table 4). Considering Table 4, it is clear that FDCIL1 is an effective catalyst for the esterification reaction of these anhydrides too.

Table 3. Comparison of the activity of some catalysts in the esterification reaction of phthalic anhydride with n-butanol.

\begin{tabular}{|c|c|c|c|c|c|c|c|}
\hline Entry & Catalyst & $\begin{array}{l}\text { PhA: n-Butanol } \\
\text { molar ratio }\end{array}$ & $\mathrm{T}\left({ }^{\circ} \mathrm{C}\right)$ & Time (h) & PhA conv. (\%) & Yield (\%) & Ref. \\
\hline 1 & Amberlyst-36 & $1: 10$ & 120 & - & 39 & - & 36 \\
\hline 2 & $\mathrm{H}_{3} \mathrm{PW}_{12} \mathrm{O}_{40}$ & $1: 2$ & 110 & 3 & 77 & - & 6 \\
\hline 3 & $\mathrm{H}_{14} \mathrm{NaP}_{5} \mathrm{~W}_{29} \mathrm{MoO}_{110}$ & $1: 2$ & 110 & 3 & 100 & - & 6 \\
\hline 4 & {$[\mathrm{emim}] \mathrm{BF}_{4}$} & $1: 2.5$ & $120-130$ & 7 & 62 & - & 9 \\
\hline 5 & Phosphinite ionic liquids & $1: 2.1$ & 100 & 3.5 & 78 & - & 37 \\
\hline 6 & {$\left[\mathrm{HSO}_{3-}\right.$ pmim] pTSA } & $1: 2.5$ & $120-130$ & 7 & 98 & - & 9 \\
\hline 7 & Sulfamic acid & $1: 4$ & $113-115$ & 4 & 81.1 & - & 38 \\
\hline 8 & Amorphous zirconium titanium phosphate & $1: 2.5$ & 115 & 10 & - & 62.4 & 39 \\
\hline 9 & $p$-Toluene sulfonic acid & $1: 2$ & 110 & 4 & 35 & - & 6 \\
\hline 10 & FDCIL1 & $1: 2.5$ & 120 & 1.5 & 100 & 98.8 & This work \\
\hline 11 & FDCIL2 & $1: 2.5$ & 120 & 1.5 & 100 & 95.1 & This work \\
\hline
\end{tabular}

Table 4. Results of esterification of maleic and succinic anhydrides with ethanol in the presence of FDCIL1 ${ }^{\mathrm{a}}$.

\begin{tabular}{lcccc}
\hline Entry & Anhydride & Time (h) & Conv. (\%) & Yield (\%) \\
\hline 1 & Maleic anhydride & 3 & 100 & 94.2 \\
2 & Succinic anhydride & 3.5 & 100 & 91.5 \\
\hline
\end{tabular}

${ }^{a}$ Reaction conditions: molar ratios of anhydride/ ethanol/ catalyst $=1: 2.5: 0.1, \mathrm{~T}=$ $120^{\circ} \mathrm{C}$. 


\section{Conclusions}

Two novel, highly acidic imidazolium based FDCILs with $\mathrm{HSO}_{4}^{-}$counter ion were synthesized, characterized and used as green and efficient catalysts for the esterification reaction of phthalic anhydride with various alcohols. The best results were obtained in the presence of FDCIL1, due to the higher acidity and low lipophilic character of the cationic side chain of this catalyst. Some valuable advantages of this method are high yields of the products, short reaction times, easy work up, not producing monoester by-product, reusability, non-toxicity, non-corrosive reagents, highly acidity of catalysts and less amounts of alcohol compared to some of the reported methods.

\section{Supplementary Informaton (SI)}

All additional information pertaining to characterization of the compounds using ${ }^{1} \mathrm{H}$ NMR and ${ }^{13} \mathrm{C}$ NMR spectra are given in the supporting information. Supplementary information is available at www.ias.ac.in/ chemsci.

\section{Acknowledgements}

We gratefully acknowledge the financial support by Malek-Ashtar University of Technology.

\section{References}

1. Wypych G 2004 In Handbook of Plasticizers (New York: ChemTec)

2. Lorz P M, Towae F K, Enke W, Jackh R, Bhargava N and Hillesheim W 2012 In Phthalic Acid and Derivatives Wiley)

3. Agrawal J P 2010 In High Energy Materials: Propellants, Explosives and Pyrotechnics (Weinheim: Wiley)

4. Provatas A 2000 Energetic Polymers and Plasticizers for Explosive Formulations - A Review of Recent Advances DSTO-TR-0966. Aeronautical and Maritime Research Laboratory, Melbourne, Australia

5. Staples C A 2003 In Phthalate Esters, The Handbook of Environmental Chemistry (Berlin: Springer)

6. Arabi M, Mohammadpour Amini M, Abedini M, Nemati A and Alizadeh M 2003 J. Mol. Catal. A: Chem. 200105

7. Thakkar R and Chudasama U 2009 Green Chem. Lett. Rev. 261

8. Sejidov F T, Mansoori Y and Goodarzi N 2005 J. Mol. Catal. A: Chem. 240186

9. Xie C, Li H, Li L, Yu Sh and Liu F 2008 J. Hazard. Mater. 151847
10. Gupta P and Paul S 2014 Catal. Today 236153

11. Cole A C, Jensen J L, Ntai I, Tran K L T, Weaver K J, Forbes D C and Davis J H 2002 J. Am. Chem. Soc. 124 5962

12. Chen S H, Zhao Q and Xu X W 2008 J. Chem. Sci. 120 481

13. Sharma P and Gupta M 2016 J. Chem. Sci. 12861

14. Nagarajan S, Shaikh T M and Kandasamy E $2015 \mathrm{~J}$. Chem. Sci. 1271539

15. Sharma S M L and Singh J 2014 J. Chem. Sci. 1261869

16. Singh P, Kumari K and Kaithwas G 2013 J. Chem. Sci. 1251471

17. Yue C, Fang D, Liu L and Yi T 2011 J. Mol. Liq. 163 99

18. Li H, Yu Sh, Liu F, Xie C and Li L 2007 Catal. Commun. 81759

19. Iglesias M, Gonzáles-Olmos R, Cota I and Medina F 2010 Chem. Eng. J. 162802

20. Pino V, Baltazar Q Q and Anderson J L 2007 J. Chrom. A 114892

21. Haddad B, Villemin D, Belarbi E H, Bar N and Rahmouni M 2014 Arab. J. Chem. 7781

22. Anderson A J L, Ding R, Ellem A and Armstrong D W 2005 J. Am. Chem. Soc. 127593

23. Liang J H, Ren X Q, Wang J T, Jiang M and Li Z J 2010 J. Fuel Chem. Tech. 38275

24. Xiong W M, Zhu Z, Deng L, Fu Y and Guo Q X 2009 Energ. Fuel 232278

25. Zhao D, Liu M, Zhang J, Li J and Ren P 2013 Chem. Eng. J. 22199

26. Fareghi-Alamdari R, Ghorbani-Zamani F and Shekarriz M 2015 J. Mol. Liq. 211831

27. Fareghi-Alamdari R and Hatefipour R 2015 Thermochim. Acta $\mathbf{6 1 7} 172$

28. Fareghi-Alamdari R, Ghorbani-Zamani F and Zekri N 2014 J. Serb. Chem. Soc. 791337

29. Rostamizadeh S, Zekri N and Tahershamsi L 2014 Polycycl. Aromat. Compd. 34542

30. Rostamizadeh S and Zekri N Polycycl. Aromat. Compd. in press, doi: 10.1080/10406638.2014.980435

31. Rostamizadeh S and Zekri N 2016 Res. Chem. Intermed. 422329

32. Rostamizadeh S, Zekri N and Tahershamsi L 2015 Chem. Heterocycl. Compd. $\mathbf{5 1} 526$

33. Fraga-Dubreuil J, Bourahla Kh, Rahmouni M, Bazureau J P and Hamelin J 2002 Catal. Commun. 3185

34. Tang T, Moyori T and Takasu A 2013 Macromolecules 465464

35. Rodriguez-Galan A, Franco L and Puiggali J 2011 Polymers 365

36. Ganapati D, Yadav G D and Mujeebur Rahuman M S M 2004 Clean Tech. Env. Policy 6114

37. Valizadeh H and Khalili E 2012 J. Iran. Chem. Soc. 9 529

38. Patil M S, Gurudasani V D and Usmani G A 2010 Curr. World Environ. 5107

39. Thakkar R and Chudasama U 2009 Green Chem. Lett. Rev. 261 